\title{
Medya Okuryazarlığı ve Yansitıcı Düşünme: Kavramsal Bir Bakış
}

DOI: 10.26466/opus.938232

\author{
Ayșegül Yılmazer* - Ünsal Bekdemir** \\ * Araş Gör., Recep Tayyip Erdoğan Üniversitesi, Rize/Türkiye \\ E-Posta: \\ aysegul.yilmazer@erdogan.edu.tr \\ ORCID: $\quad$ 0000-0002-1331-9243 \\ ** Prof. Dr., Giresun Üniversitesi, Giresun/Türkiye \\ E-Posta: unsal.bekdemir@giresun.edu.tr \\ ORCID: $\quad$ 0000-0002-7767-9088
}

Öz

21. yüzyıl için vazgeçilmez bir yaşam becerisi olarak ifade edilen medya okuryazarlığı konusunda yapılan araştırmalara bakıldığında, çalışmaların genellikle medya okuryazarlığının eğitim müfredatlarında ders olarak yer alması, dersin içeriği, amaçları, hedefleri ve medya okuryazarlığının

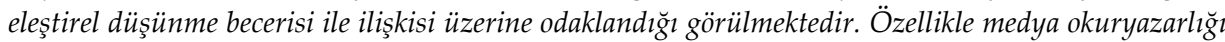
ve düşünme becerileri üzerine yapılan çalışmalara bakıldığında ise çalışmaların büyük oranda eleştirel düşünme becerisi üzerine odaklanıldığı dikkat çekmektedir. Oysa eleştirel düşünme, düşünme becerilerinden sadece biridir ve diğer düşünme becerilerinin de medya okuryazarlığı ile ilişkisinin ortaya konulmasının önemli olduğu düşünülmektedir. Bu araştırmada yansıtıcı düşünme becerisi üzerine odaklanılmıştır. Araştırmada, nitel analiz yöntemlerinden doküman incelemesi tekniği kullanılmıştır. Doküman incelemesi, araştırılması hedeflenen olgu ve olaylar hakkında bilgi içeren yazll materyallerin analizini kapsar. Nitel araştırma yapanlar genellikle kendilerinden önceki araştırmaları inceler, alan yazını gözden geçirir ve bu bilgileri araştırmalarına dâhil ederler. Bu araştırmada medya okuryazarlı̆̆ ve yansıtıcı düşünme alanında yapılmış çalışmalar incelenmiş ve alan yazın gözden geçirilmiştir. Gözden geçirilen bu bilgiler araştırmaya dâhil edilerek yansıtıcı düşünme ile medya okuryazarlı̆̆ı arasında nasıl bir ilişki olduğu ortaya konulmaya çalışılmış ve konuya genel bir bakış açısı kazandırmak amaçlanmıştır.

Anahtar Kelimeler: Okuryazarlık, Medya Okuryazarlı̆̆ı, Yansıtıcı Düşünme. 


\title{
Media Literacy and Reflective Thinking: A Conceptual Overview
}

\begin{abstract}
Considering the studies on media literacy, which is regarded as an indispensable life skill for the 21st century, it is seen that the studies generally focus on the inclusion of media literacy as a course in education curricula, the content of the course, its goals, objectives, and the relationship between media literacy and critical thinking skills. It is noteworthy that studies especially on media literacy and thinking skills mostly focus on critical thinking skills. However, critical thinking is only one of the thinking skills, and it is thought that it is also important to reveal the relationship between other thinking skills and media literacy. This research will focus on reflective thinking skills. In the research, document analysis technique which is one of the qualitative analysis methods was used. Document review covers the analysis of written materials containing information about the facts and events aimed to be investigated. Qualitative researchers generally review previous research and the literature. They also incorporate the information emerged from this review into their research. In this research, the literature in the field of media literacy and reflective thinking was examined and then synthesized. By including the review of research, we tried to reveal the relationship between reflective thinking and media literacy. Furthermore, we aimed at gaining a general perspective on the subject.
\end{abstract}

Key Words: Literacy, Media Literacy, Reflective Thinking. 


\section{Giriş}

Okuryazarlık en genel anlamı ile yazılı metinlerin okunması ve yazılması olarak tanımlanmıştır (Longman, 2020). Ancak okuryazarlık kavramı içinde bulunduğumuz yüzyılda okuma ve yazmanın, basit sayısal işlemlerin nasıl gerçekleştirildiğinden çok daha fazla anlama sahiptir (Hobbs, 2010, s.16). Sadece önünüzdeki metni okuyup anlamay1 değil, aynı zamanda küresel bir elektronik kütüphane içinde bilgi edinme, kod çözme, değerlendirme ve düzenleme gibi geniş bir beceri yelpazesini içene almaktadır (Warlick, 2004, s.20). Yüzyılımızın bütün süreçlerinde beceri odaklı bir var olma mücadelesi görülmekle birlikte her dönemin kendine özgü beceri setleri de bulunmaktadır. İçinde bulunduğumuz çağda bu beceri setlerini ifade etmek için kullanılan çatı kavram "21. yüzyıl becerileri" dir (Erişti ve Erdem, 2018, s.1235). Bu beceri setleri içerisinde yer alan medya okuryazarlığ1 21. yüzyıl için vazgeçilmez bir yaşam becerisidir (Bergsma, 2002, s.16).

Medya okuryazarlığı; televizyon, radyo, bilgisayar, gazete, dergi ve reklamlarda karşılaştığımız sözlü ve görsel sembollerden kişisel anlam oluşturma, etrafımızda olup bitenlerle ilgili edilgen ve savunmasız olmama, sorgulama, şüphe duyma, seçme ve ayırt etme yeteneğini ifade eder (Thoman, 1999, s.50). Her yaştan bireyin eleştirel bir düşünür, etkili bir iletişimci ve günümüz dünyasında aktif bir vatandaş olması için ihtiyaç duydukları sorgulama alışkanlıklarını ve ifade becerilerini geliştirmelerine yardımcı olmak amacında olan medya okuryazarlığ1 (Scheibe ve Rogow, 2012, s.60) medyayı "okuma" ve "yazma" -yı içerir. Gençlerin medya tüketicileri olarak bilgiye dayalı yargıda bulunmalarına ve yorum yapmalarına olanak sağlamakla birlikte kendi başlarına bir medya üreticisi olmalarını da sağlar (Meigs, 2006, s.20).

Medyanın farklı araçlar ve kanallar aracılığı ile bireyler üzerindeki yoğun ve hızlı etkileri, bilinçli medya okuryazarı bireylerin yetiştirilmesini gerektirmektedir (Kurt ve Kürüm, 2010, s.20). Birçok eğitimci, geleceğin iş gücünü oluşturacak ve toplumsal hayatta söz sahibi olacak yeni nesillerin, bilgiyi öğrenme ve anlamlandırma becerilerinin, bilginin kendisinden çok daha önemli olduğu görüşündedir (Gough, 1991, s.3). Günümüzde bilmek değil, onu işleyebilmek, irdeleyebilmek daha önemlidir. Bu sebeple eğitim sistemi 
öğrencilere düşünme becerilerini kazandırmayı hedeflemiştir (Bacanlı, 2012, s.30). Düşüme becerilerini kazandırma öğretimin özüdür (Özden, 1999, s.92). Medya okuryazarlığının da bireylerin medya tüketiminde daha bilinçli kişiler olmaları ve bir takım düşünme becerilerine sahip olmaları gerektiği görüşüne dayandığı söylenebilir (Kurt ve Kürüm, 2010, s.21).

Medya okuryazarlığı konusunu çalışan birçok araştırmacı medya okuryazarlığını öncelikle bir beceri olarak düşünür ve bu beceriye atıfta bulunmak için eleştirel düşünme kavramını kullanır (Potter, 2016, s.59). Yapılan araştırmalara bakıldığında da bu durum dikkat çekmekte ve medya okuryazarlı̆̆ ile eleştirel düşünme arasındaki ilişkinin birçok kez farklı kişilerce çalışıldığ görülmektedir. Altıntaş, (2009); Arke, (2005); Aybek, (2016); Aybek ve Demir, (2013); Bakan, (2010); Chen, (2015); Çarkıt, (2019); Çelik, Çokçalışkan ve Yorulmaz (2018); Erişti ve Erdem (2018); Feuerstein, (2002); Karaman, (2016); Kurt ve Kürüm, (2010); Nalçatı, Meral, Şahin (2016); Silverblatt (2018); Thayer, (2006); Ulu ve Baş, (2020), Yıldırım Ankaralıgil, (2009); Yüzgeç, (2020) yaptıkları araştırmalarında medya okuryazarlığ ve eleştirel düşünme becerisi üzerine odaklanmışlardır. Oysa eleştirel düşünme, düşünme becerilerinin sadece biridir ve farklı düşünme becerilerinin de medya okuryazarlığına atıfta bulunmasının önemli olduğu düşünülmektedir. $\mathrm{Bu}$ düşünme becerilerinden biri de yansitıcı düşünmedir. Literatüre hâkim olmayan bir kişi eleştirel düşünme ve yansıtıcı düşünme becerilerinin genellikle ayn anlama geldiğini düşünülebilir. Oysa her iki düşünme becerisi birtakım benzerliklere sahip olmakla birlikte birçok farklılığ 1 da içinde barındırmaktadır.

Altın ve Saracaloğlu (2018) yaptıkları çalışmada yaratıcı, eleştirel ve yansitıcı düşünmenin benzerlikleri ve farklılıklarını 72 doktora tezi üzerinde incelemişlerdir. Çalışmalarının sonucunda her üç düşünme şeklinin bireyin çok yönlü olması, bilgiyi kullanmada ve sonuca ulaşmada birden fazla yaklaşımı benimsemesi gibi genel hatlarda benzerlikler gösterdikleri, ancak bilgilerin kullanılmasında izlenen yollar, ortaya çıkan sonuç ve bireyin bu süreçteki rolü bakımından ayrıldığı sonucuna ulaşmışlardır. Araştırmanın dikkat çeken sonuçlarından bir diğeri ise incelenen doktora tezlerinin yarısından fazlasının eleştirel düşünme ve yaratıcı düşünme üzerine olduğu ancak 
sadece 11 doktora tezinde yansitıcı düşünmeye yer verildiğidir. Bu veriden yola çıkarak yansıtıcı düşünme konusunda alanyazının güçlendirilmesi gerektiği sonucuna ulaşmışlardır.

Yansitıcı düşünme ve eleştirel düşünme terimleri, belirsizliği ve ikilemleri kabul eden bir düşünme biçimini tanımlamak için kullanılır. Bir problemin anlaşılması sürecinde ortaya çıkan ikilem, yansıtıcı düşünen kişiyi hem mevcut sonuçların eleştirisine hem de yeni hipotezlerin oluşturulmasına dâhil olan aktif bir sorgulamaya yönlendirir (Larrive, 2000, s.294). Yansitıcı düşünme eleştirel düşünmeyi içinde barındıran daha kapsamlı bir düşünme biçimi olup, eleştirel düşünme yansitıcı düşünmenin ürünü sayılabilir (Altın ve Saracaloğlu, 2018, s.6). Yansitıcı düşünme; uyaranlara anında yanit vermenin ötesinde bir şey hakkında derin, ciddi ve konsantre bir şekilde düşünmek anlamına gelir. Yansıtma yapıldığında sadece ani bir hareketle düşünce oluşturulmaz, alternatifler dikkate alınır, sonuçlar çıarılır, mevcut kanıtlar tartışılır ve hipotezler test edilir (Butterworth ve Thwaites, 2013, s.2). Ersözlü (2008, s.30), yansıtıcı düşünmenin, eleştirel, yaratıcı, biliş ötesi düşünme ve problem çözmeyi kapsayan daha genel bir düşünme becerisi olduğunu söyler.

Medya okuryazarlığı ve yansıtıcı düşünme kavramları kapsamlı bir şekilde incelendiğinde iki kavram ya da beceri arasında birçok ortak yönün olduğu dikkat çekmektedir. Bu iki beceri arasında nasıl bir ilişki olduğuna bir cevap niteliğinde olan bu araştırmada aşağıdaki sorulara yanit aranmiştır:

- Medya okuryazarlığı nedir?

- Yansitıci düşünme nedir?

- Medya okuryazarlığ1 ve yansitıcı düşünme arasında kavramsal çerçevede nasıl bir ilişki kurulabilir?

Bu sorulardan yola çıkarak bu araştırmada; medya okuryazarlığı ve yansıtıcı düşünme kavramları, bu alanda hazırlanmış kavramsal ve uygulamalı çalışmalara dayanarak incelenmiş ve konuya genel bir bakış açısı kazandırmak amaçlanmıştır. 


\section{Yöntem}

$\mathrm{Bu}$ araştırmada nitel araştırma yöntemlerinden biri olan doküman incelemesi kullanılmıştır. Doküman incelemesi veya analizi tek başına bir araştırma yöntemi olabildiği gibi, diğer nitel yöntemlerin kullanıldı̆̆ı durumlarda ek bilgi kaynağ1 olarak da kullanılabilir. Bu tür araştırmalarda araştırmacı ihtiyacı olan veriyi, gözlem ve görüşme yapmaya gerek kalmadan elde edebilir (Yıldırım ve Şimşek, 2018, s.189190). Nitel araştırmada kullanılan diğer yöntemler gibi doküman analizi de anlam çıkarmak, ilgili konu hakkında bir anlayış oluşturmak, ampirik bilgi geliştirmek için verilerin incelenmesini ve yorumlanmasını gerektirmektedir (Corbin ve Strauss, 2008; Akt. Kiral, 2020, s.173). Araştırmacılar genellikle kendilerinden önceki araştırmaları inceler, alan yazını gözden geçirir ve bu bilgileri araştırmalarına dâhil ederler. Bu analitik bir yöntemi içermektedir (Kıral, 2020, s.175).

$\mathrm{Bu}$ araştırmada medya okuryazarlığı ve yansıtıcı düşünme alanında yapılmış çalışmalar incelenmiş, alan yazın gözden geçirilmiş ve bu bilgiler araştırmaya dâhil edilerek yansıtıcı düşünme ile medya okuryazarlığı arasında nasıl bir ilişki olduğu ortaya konulmaya çalışılmış ve konuya genel bir bakış açısı kazandırmak amaçlanmıştır.

\section{Medya Okuryazarlı̆̆}

TÜIKK ve MEB tarafından yapılan çeşitli araştırmaların bulgularında okuryazarlık oranının ortalama \%97 olduğu görülmektedir. Okuryazar oranının yüzde yüzlere yaklaşmasıyla okuma yazma bilmek bir ayrıcalık olmaktan çıkmıştır. Günümüzde insanlar zaten okuryazar olmak durumundadır ancak içinde bulunduğumuz yüzyılda medya ile kuşatılmış bir insanın medyanın dilini okuyabilmesi çok daha büyük bir önem kazanmıştır (Bilici, 2017, s.2).

Celot (2010, s.22), medya okuryazarlığını, bilgi toplumu içinde ve bunun sonucunda oluşan iletişim ve medya ortamı ile özerk ve eleştirel olarak başa çıkma yetkinliği olarak tanımlar. Medya okuryazarlı̆̆ının basit bir teknik beceri, örneğin bir medya platformunun kullanımı değil, aynı anda sayısız bilgi kaynağının eleştirel anlayışı, analitik okunması ve 
akıl yürütülmesi olduğunu ifade eder. Altun (2010, s.17) medya okuryazarlığını, okuma ve yazma, konuşma ve dinleme, yeni teknolojilere ulaşma, eleştirel bakma, kameralardan bilgisayarlara kadar çeşitli teknolojileri kullanarak kendi mesajını üretme yeteneği olarak tanımlar. Medya okuryazarlığının çağdaş toplumda maruz bırakıldığımız pek çok çeşitlilikteki mesajlara uzanan bir okuryazarlığı kapsadığını ifade eder. Medya okuryazarlığının ne yeni bir konu alanı olduğunu ne de sadece televizyonla ilgili olduğunu belirterek, bilgi çağ için gerekli olan okuryazarlık olduğunu söyler. 1992 yılında Aspen Enstitüsü tarafından desteklenen Ulusal Medya Okuryazarlığ Konferansı'nda, grup temsilcilerinin medya okuryazarlığının ortak vurgulamalarından yola çıkarak yaptıkları tanımın medya okuryazarlığı konusunda yapılan en kapsamlı tanım olduğu ileri sürülebilir. Bu tanıma göre medya okuryazarlığı, "çeşitli biçimlerde mesajlara ulaşma, analiz etme, değerlendirme ve iletme" yeteneği olarak ifade edilmiştir (Aufderheıde ve Firestone, 1992, s.1).

Literatür incelendiğinde, "medya okuryazarlığ1 nedir?" sorusuna birbirine benzer ancak birbirinden oldukça farklı yantlar verildiği görülmektedir. Tyner (1991) medya okuryazarlı̆̆1 kavramını tanımlamanın zorluğunu, Hindistan'da bir halk masalı olan "Kör Adamlar ve Fil" masalına benzetir. Medya okuryazarlığını tanımlamak isteyen kişilerin resmin sadece bir parçasına odaklandıklarını, diğer taraflarını görmediklerini, dolayısıyla doğru bir tanım yapılması için resmin tamamına bakılması gerektiğini söyler (Tyner, 1991).

Medya okuryazarlığı nasıl tanımlanırsa tanımlansın, dinamik, çok yönlü, uyarlanabilir, sürekli genişleyen, gözlemlenebilen ancak doğrudan ölçülemeyen bir olgu olup, (Celot, 2010, s.23) doğası gereği disiplinler arası bir kavramdır. Medya okuryazarlığı bizi çevreleyen karmaşık, sürekli değişen elektronik ortam ve iletişim dünyası için gerekli, kaçınılmaz ve gerçekçi bir tepkiyi temsil etmektedir. Başarılı bir öğrenci, sorumlu bir vatandaş, üretken bir işçi veya yetkin ve vicdan sahibi bir tüketici olmak için medya okuryazarlığı becerisine ihtiyaç vardır (NAMLE,2007). Bu beceri kasıtlı bir şekilde eğitim sürecine dâhil edilmelidir. Medya okuryazarlığı becerilerini öğrenme süreci medya okuryazarlığı eğitimi olarak ifade edilir. Öğrencilere medya teknikleri ve etkisine ilişkin bilgi ve eleştirel bir anlayış kazandırmak amacında olan 
medya okuryazarlığı eğitimi (Quin ve McMahon, 2001, s.311) bireylerin, medya kurumunun yapısı ve işleyiş̧ini öğrenmelerini, kurgu ile gerçeği birbirinden ayırarak bu içerikleri bilinçli bir şekilde değerlendirebilmelerini ve onlara medya içeriklerini eleştirel bir şekilde izleme ve medya ile ilgili doğru soruları sorup doğru yantları bulabilmeleri konusunda gerekli donanımları kazandırmaktadır (Karaboğa, 2017, s.387). Her yaştan bireyin eleştirel bir düşünür, etkili bir iletişimci ve günümüz dünyasında aktif bir vatandaş olması için, bireylerin ihtiyaç duydukları sorgulama alışkanlıklarını ve ifade becerilerini geliştirmelerine yardımcı olmaktadır (Scheıbe ve Rogow, 2012, s.60). Önemli olan nokta çocukların istenmeyen mesajlara ulaşmalarını engellemek değildir. Bazı gruplar, aileleri sadece televizyonlarını kapatmaları yönünde zorlamalarına rağmen gerçekte medyayı kültürel ortamımızdan çıkarmak mümkün olmayacaktır. Çünkü medya artık sadece kültürümüzü etkileyen bir öğe olmayıp, medya bizim kültürümüz durumundadır (Thoman ve Jolls, 2005, s.21). Medya okuryazarlığı eğitimi de medyanın kültürün bir parçası olduğunu ve sosyalleşmenin bir aracı olarak işlev gördügünü kabul etmektedir (NAMLE,2007).

Medya okuryazarlığı; demokratik süreçleri etkilemesinin yanı sıra algılar, inançlar ve tutumları şekillendirme üzerindeki etkisi, görsel iletişim ve bilginin artan önemi, yaşam boyu öğrenmenin gerekliliği gibi sebeplerle de oldukça önemlidir. (Thoman ve Jolls, 2005, s.9). Gençlerin önemli gördükleri yaşam seçimleri üzerinde düşünmelerine, sağlıklı kararlar vermelerine yardımcı olarak medya mesajları ile kontrol edilmeleri yerine medya mesajlarını kontrol etmelerini sağlar (Bergsma, 2002, s.14).

Medya okuryazarlığının dayandığı bir takım temel ilkeler bulunmaktadır. Bu temel ilkeleri bilmek nitelikli bir medya okuryazarlığı eğitiminin ve iyi bir medya okuryazarı olabilmenin ön koşuludur. Medya okuryazarı olmayan bireyler medyada karşılaştıkları herhangi bir bilgiyi makul değerlerde kabul etme eğilimindedirler. Ancak bu beceriye sahip olan bireyler medya okuryazarlığı ilkeleri ile medyanın gerçekliğin kendisi olmadığını ve inşa edildiğini öğrenirler. Medya Okuryazarlığ Eğitimi Ulusal Birliği (NAMLE,2007) medya okuryazarlığ temel ilkesini şöyle açıklamıştır. Medya okuryazarlığı eğitimi; 
- Aldığımız ve oluşturduğumuz mesajlar hakkında aktif sorgulama ve eleştirel düşünme gerektirir.

- Okuryazarlık kavramını her türlü medya formlarını içerecek şekilde genişletir.

- Her yaştan öğrencinin becerilerini geliştirir ve pekiştirir. Basılı okuryazarlıklar gibi bu beceriler de entegre, etkileşimli ve tekrarlanan uygulamaları içerir.

- Demokratik bir toplum için gerekli olan bilinçli, yansıtıcı ve katılımcı bireyler geliştirir.

- Medyanın, kültürün bir parçası olduğunu ve sosyalleşmenin bir aracı olduğunu kabul eder.

- Bireylerin medya mesajlarından kendi anlamlarını oluşturmaları için bireysel becerilerini, inançlarını ve deneyimlerini kullanmaları gerektiğini belirtir.

Medya okuryazarlığı ilkeleri ile medyanın gerçekliğin kendisi değil inşa edilmiş bir şekli olduğunu öğrenen bireyler karşılaştıkları her türlü bilgiye şüphe ile bakmaları gerektiğini öğrenirler. Bu ilkelere dayalı olarak, kişilerin medya mesajlarını değerlendirmeleri için sormaları gereken temel sorular belirlenmiştir. Medyanın etkilediği bir toplumda, kişilerin etkili bir yetişkin olabilmek için karşılaştıkları her türlü medya ürününü sorgulayabilecek "temel bilgi ve anahtar soruları" bilmeye ihtiyaçları vardır. Thoman ve Jolls $(2005$, s.15) bu bilgi ve soruları şöyle açıklamıştır.

Tablo 1. Medya Okuryazarlığında Beş Temel Bilgi ve Beş Anahtar Soru

\begin{tabular}{ll}
\hline Beş Temel Bilgi & Beş Anahtar Soru \\
\hline 1.Medya mesajlarının tamamı kurgulanmıştır. & 1.Bu mesaj kim tarafından oluşturuldu? \\
$\begin{array}{l}\text { 2.Medya mesajları kendine özgü kurallar kullanılarak2.Bu mesajda dikkat çekmek için hangi yaratıcı } \\
\text { yaratıcı bir dille kurgulanmıştır. }\end{array}$ & $\begin{array}{l}\text { teknikler kullanıldı? } \\
\text { 3.Aynı mesajı farklı kişiler farklı şekilde anlayabilirler. 3.Bir mesajı farklı insanlar neden farklı şekilde } \\
\text { anlarlar? }\end{array}$ \\
$\begin{array}{ll}\text { 4. Medyanın gizlenmiş değer ve görüşleri vardır. } & \begin{array}{l}\text { 4. Bu mesajda hangi yaşam biçimleri, değerler ve } \\
\text { görüşlere yer verilirken hangileri göz ardı edilmiştir? }\end{array} \\
\text { 5. Medyadaki mesajların büyük çoğunluğu kazanç ya5. Bu mesaj neden gönderilmiştir? } \\
\text { da güç elde edebilmek için oluşturulmuştur. }\end{array}$
\end{tabular}

$\mathrm{Bu}$ beş anahtar soruyu sormayı öğrenmek, bisiklete binmeyi veya yüzmeyi öğrenmek gibidir. Pratik yapmayı gerektirir ve öğrenmesi zaman alır. Öğrenildikten sonra ise kişiler yaşlarına ve kabiliyetlerine 
uygun olarak medya mesajlarına soru sormaya alışır ve süreç giderek otomatikleşir (Thoman ve Jolls; 2004, s.24). Medya mesajlarını değerlendirmek için öğrenciler sadece doğru veya yanlış, gerçekçi veya yanıltıcı, basmakalıp veya kesin olarak değil, aynı zamanda dünya hakkında belirli ilgi alanları veya varsayımları olan, etkilenilebilecek veya değiştirilebilecek sesler olarak görmeyi de öğrenirler (Lewis ve Jhally, 1998, s. 119).

Kısaca medyanın dilini öğrenmek anlamına gelen medya okuryazarlığı, içinde bulunduğumuz çağda hem öğrenciler hem de tüm bireyler için vazgeçilmez bir yaşam becerisi olup, karşımıza çıkan her türlü medya mesajını, medya okuryazarlığının temel kavramları ve anahtar soruları kapsamında değerlendirmemizi gerektirir.

\section{Yansitıcı Düşünme}

Düşünme en basit anlamıyla zihnimizde olan ve aklımızdan geçen her şeyi ifade eder (Dewey, 1933, s.3). Düşünme zihnimizin sınırsız bir becerisidir ve bu süreçte zihnimizde peş peşe mantıklı işlemler yapılmaktadır. Düşünme sürecinde yürütülen zihinsel işlemler birbirinden farklı olmakta ve çeşitli bilgiler gerektirmektedir. $\mathrm{Bu}$ işlemlere akıl yürütme denilmekte ve akıl yürütmenin belirli bir mantığa göre yapılması düşünme türlerini oluşturmaktadır (Güneş, 2012, s.131). $\mathrm{Bu}$ düşünme çeşitlerinden biri olan yansitıcı düşünme; uyaranlara anında yanıt vermenin ötesinde bir şey hakkında derin, ciddi ve konsantre bir şekilde düşünmek, (Butterworth ve Thwaites, 2013, s.2) kendi öğrenme ve öğretme sürecine ilişkin sorgulama yapmak, kendini değerlendirmek, bu sorgulama ve değerlendirme sonucunda ortaya çıkan sorunları çözmek için neler yapabileceğini düşünmek anlamına gelir (Ersözlü, 2008, s.29). Yansıtıcı düşünme; bireyin günlük yaşantıları ile ilgili varsayımlarını incelemesi ve farkında olması, kendi içinde bulunduğu durumu eleştirel olarak değerlendirebilmesidir (Finlay, 2008, s.1). Yansitıcı düşünme bir zincirdir ve fikirlerin sonucudur. Yansitıcı düşünmenin birbirini izleyen kısımları birbirinden büyür ve birbirini destekler. Her aşama bir sonraki aşamada kullanılacak olan bir öğrenme unsurunu içerir. Yansıtıcı düşünme bir sonuca ya da düzeltilmek istenen bir hedefe yöneliktir. Bu fikir dizisi yansıtıcı birimleri birbirine bağlar 
böylece ortak bir amaca doğru sürekli bir hareket olur (Dewey, 1933, s.15).

Ünver (2011, s.137), yansıtıcı düşünmenin anlamını dört boyutta açıklamıştır:

- Yansitıcı düşünmede görüşler yalnızca basit bir biçimde sıralanmaz; görüşler arasında anlamlı ilişkilere dayanan bir ardışıklık söz konusudur. Bir görüş kendisinden önceki görüşe dayanır ve kendisinden sonraki görüşün uygunluğuna karar verir.

- Yansiticı düşünmede olgular ve olaylara ilişkin duygu ve inançlar üzerinde durulur. Yansitıcı düşünme, duyguları olumlu duruma getirme ve geliştirmeyi amaçlar.

- Yansitıcı düşünme, inancı bazı temellere dayandırır. Algılanılan ya da düşünülen durumlar mantıksal olarak uygun olup olmama koşuluna göre kabul ya da reddedilir.

- Yansitıci düşünme bir inancın doğasına, koşullarına ve temellerine ilişkin bilinçli bir araştırma yapmayı gerektirir.

Yansıtıcı düşünmede amaç kişinin yeni anlayışlar kazanması ve gelecekteki yaşantısını geliştirmek için deneyimlerini tekrar ele alarak eleştirel olarak gözden geçirmesidir. Bu yaşam boyu öğrenme sürecinin bir parçası olarak anlaşılmalıdır (Finlay, 2008, s.1). Yansıtma yaptığımızda sadece ani bir hareketle düşüncelerimizi oluşturmayız, alternatifleri dikkate alır, sonuçlar çıkarır, mevcut kanıtları tartışır ve hipotezleri test ederiz (Butterworth ve Thwaites, 2013, s.2). O halde yansıtma açıkça bir amaca yöneliktir çünkü bir sonuca varmayı hedeflemektedir. Derinlemesine düşünmenin amac1, bir sorunu çözmek veya kafa karıştırıcı bir durumu daha fazla anlamlandırmaktır (Loughran, 1996, s.23).

Başlangıç olarak "yansıt" kelimesi geriye bakmayı gerektirir. Kendimizi öğrenme sürecinin bir parçası haline getirmek için düşünmemiz gerekir. Ayrıntıları ortaya çıkarmak için ise hayal gücüne ihtiyacımız vardır (Judge, Jones, ve McCreery, 2009, s.48). Ayrıca yansıtıcı düşünen kişi yalnızca çözülecek soruna, alınacak karara veya kazanılacak argümana değil aynı zamanda bu faaliyetlere giren muhakeme süreçlerine de odaklanmaktadır. Düşünme şeklimizi düşünmek veya düşünmeyi düşünmek, düşünmemizin ne kadar etkili 
olduğunu, güçlü yanlarının neler olduğunu, bazen yanlış gittiğini ve en önemlisi nasıl geliştirilebileceğini değerlendirmemize yardımcı olur (Butterworth ve Thwaites, 2013, s.2).

Sıklıkla yansitıcı düşünme ve eleştirel düşünme terimleri belirsizliği ve ikilemleri kabul eden bir düşünme biçimini tanımlamak için kullanılır. Bir problemin anlaşılması sürecinde ortaya çıkan ikilem yansıtıcı düşünen kişiyi hem mevcut sonuçların eleştirisine hem de yeni hipotezlerin oluşturulmasına dâhil olan aktif bir sorgulamaya yönlendirir (Larrive, 2000, s.294). Eleştirel düşünme ile yansitıc1 düşünmenin öncelikleri farklıdır. Eleştirel düşünme; bireyin bütün bilgileri, fikirleri, gözlemleri, tartışmaları, olayları, iletişimleri mantıklı bir biçimde değerlendirilmesine odaklanırken, yansıtıcı düşünme; bireyin deneyimleri üzerinde eleştirel bir şekilde düşünerek, problemi belirlemesi ve çözmesi, geleceğe yönelik düşünce ve fikirlerini yeniden yapılandırması üzerine odaklanır (Tican, 2013, s.32). Yansıtıcı düşünme; eleştirel, yaratıcl, biliş ötesi düşünme ve problem çözmeyi kapsayan daha genel bir düşünme becerisidir. Yansitıcı düşünen birey, problem çözme becerilerine sahiptir, bir başka deyişle, karşısına çıkan problemleri algılayarak, çözüme ilişkin verileri toplar, çözümleri test eder ve bu yolla doğru sonucu keşfeder. Eleştirel düşünebilir, herhangi bir durum ya da bilgi karşısında sorgulama yapabilir, var olan duruma ilişkin çıkarımlarda bulunabilir ve diğerleriyle etkileşim halinde olabilir. Ayrıca yaratıcı düşünebilir, elindeki seçeneklerin neler olduğunu bilir ve yeni fikirler ortaya atabilir, kendi öğrenme, düşünme sürecinin farkında olarak kendini yönetebilir (Ersözlü, 2008, s.30).

Günümüzde bilmek değil, onu işleyebilmek, irdeleyebilmek çok daha önemli olduğu için eğitim sistemi öğrencilere düşünme becerilerini kazandırmayı hedeflemektedir (Bacanlı, 2012, s.30). Düşüme becerilerini kazandırma öğretimin özüdür (Özden, 1999, s.92). Öğretimde öğrencilere kazandırılması istenen düşünme becerilerinden biri olan yansıtıcı düşünme; hem öğretmenler hem de öğrenciler için öğrenme sürecinin vazgeçilmez bir unsurudur (Tok, 2008, s.106). Çünkü yansıtıc1 düşünme ile öğrenciler kendi öğrenmelerinin bilincinde olur, güçlü ve zayıf yönlerini bilir, zayıf yönlerini geliştirmek için çaba gösterir ve ortaya çıkan sorunları gidermeye yönelik bir girişimde bulunur (Ersözlü, 2008, s.4). Yansıtma, öğrenenin sonuçtan daha çok sürece odaklanmasını 
gerektirir. Yansıtmanın olabilmesi için öncelikle öğrenmenin gerçekleşmiş olması ve bireyin öğrendiğini davranışa dönüştürebilmesi gerekir. Bu aşamadan sonra ortaya konan davranışın özellikle öğrenci tarafından değerlendirilmesi söz konusudur (Ceran, 2017, s.226). Yansıtıcı uygulamanın amacı kişisel ve toplumsal bazda öğrenmeyi artırmaktır. Bu nedenle yansıtıcı düşünmeyi harekete geçirmek, yansıtıcı uygulamayı geliştirmek ve içselleştirmek için çeşitli stratejiler ve teknikler kullanılmaktadır. Kullanılan bu tekniklerin ortak amacı özetle;

- Hedeflenen amaca ulaşılıp ulaşılmadığını görebilmek için süreci gözden geçirmek,

- Bakış açımızı ve anlayışımızı geliştirmek,

- Öğrenmeyi somutlaştırmak, hayatımızdaki her olay için öğrenme döngüsünü tamamlamak,

- Bir olaya daha düşünülmüş cevaplar verebilmek,

- Kendimize ve eylemlerimize değer katmak,

- Acemilikten uzmanlığa geçmektir (York-Barr ve Diğ. 2006, s.17, akt. Dalg1ç, 2011, s.34).

Yansıtıcı düşünmeyi geliştirmek için; öğrenme yazıları, kavram ve zihin haritaları, soru sorma, kendine soru sorma, anlaşmalı öğrenme, kendini değerlendirme gibi yaklaşımlardan faydalanılabilir (Ünver, 2011, s.140-143; Güney, 2008, s.41). Yansitıcı düşünmeyi geliştirme; yansıtıcı günlük, işbirliği, portfolyo, tartışma, mikro-öğretim, eylem araştırması, gözlem, durum çalışmaları, akran rehberliği, otobiyografi gibi etkinliklerle yapılabilir (Tican, 2013, s.41). Öğrenmeyi geliştirmenin en iyi yollarından biri, öğrenme deneyimi ile onu izleyen yansitıcı faaliyet arasındaki bağlantıyı güçlendirmektir. $\mathrm{Bu}$ bağlantıyı güçlendirmek en basit şekilde yansıtma için vakit ayırmak ile mümkün olabilir. Yansitıcı süreçte önemli olduğuna inanılan üç aşama Boud, Keogh ve Walker (2005, s.26) tarafından şu şekilde açıklanmıştır.

- Deneyime Geri Dönme: Bu süreçte önemli olan şey olayların hatırlanması, kişinin zihnindeki ilk deneyimin tekrarlanması veya olayın özelliklerinin başkalarına yeniden anlatılması ve olayın ayrıntılarına inilmesi.

- Duygulara Katılma: Faydalı duyguları kullanma ve zorluk çıkaranları ortadan kaldırma veya onlarla başa çıkmayı öğrenme. 
- Deneyimi Değerlendirme: Başa gelen olayı mevcut bilgisi ışığında yeniden değerlendirme.

Öğretmenlerin yansıtıcı düşünmeyi mesleki hayatlarında benimsemeleri isteniyorsa, bunu hizmet öncesi öğretmen eğitimi programlarında öğrenenler olarak bizzat deneyimlemeleri gerekmektedir (Loughran, 1996, s.6). Bu deneyimi hizmet öncesi eğitimlerinde kazanan öğretmen adayları yansitıcı öğretmenler olabileceklerdir. Yansitıcı öğretmenler, sürekli öğrenme ve iyileştirmeyi teşvik eden bir sorgulama yaklaşımı uygularlar. Bu yaklaşım öğretmenin, öğretim kararlarının kalitesini ve etkililiğini düzenli olarak analiz etmesini, değerlendirmesini ve güçlendirmesini sağlar (Carey, 2017, s.8). Larrive (2000, s.293) öğretmenlerin eleştirel düşünme pratiğini geliştirmedikleri sürece, incelenmemiş yargılara, yorumlara, varsayımlara ve beklentilere sıkışıp kalacaklarını ifade etmiştir. Öğretime yansıtıcı bir uygulayıcı olarak yaklaşmanın, kişisel inançların ve değerlerin profesyonel kimlikle birleştirilmesi gerektiğini belirtmiştir. Dolayısıyla öğretmenlerin düşünme pratikleri geliştirilmek isteniyorsa onlara yansıtıcı bir uygulayıcı olmanın yolları öğretilmelidir, bu şekilde öğrencilerin de yansitıcı birer öğrenen olmalarına fırsat verilmiş olacaktır. Çünkü eğitim kurumlarında gerçekleştirilen tüm öğrenmelerin temel taşı olan öğretmenler (Hardiyanti, 2018, s.507) öğrencilerine teşvik ettikleri pedegojileri ve stratejileri öncelikle kendileri öğrenmek zorundadır. $\mathrm{Bu}$ durum özellikle bilgi toplumu dünyasında topluma hizmet eden öğretmenler için öğrencilerden bekledikleri rolleri önce kendilerinin yansitmaları gerekliliğini ortaya koyar (Carlsson, 2019, s.64). Rodgers (2002, s.864) öğretmenlerin kendi deneyimlerinden öğrenmeyi başardıklarında iyi birer öğretici olabileceklerini savunmuş ve öğretmenlerin yansıtıcı düşünmeyi öğrendikten sonra öğrencilerine öğretmeleri gerektiğini belirtmiştir.

$\mathrm{Bu}$ bağlamda düşünüldüğünde yansıtıcı düşünmenin lisans düzeyinde uygun olan derslerle ilişkilendirilmesi ve farklı etkinliklerle geliştirilmesi yönünde çaba harcamak önemlidir. Medya okuryazarlı̆̆ı, yansitıcı düşünme becerisinin dâhil edilebileceği dersler arasında sayılabilir. 


\section{Medya Okuryazarlığı ve Yansitıcı Düşünme}

Okuryazar olmak sadece bir şeyi bilmek değil, aynı zamanda bilgi üretme eylemine yansıtıcı olarak nasıl katılacağınızı bilmek anlamına da gelir. Bununla birlikte demokratik bir devletin inşasına katkıda bulunmada hem olumlu hem de olumsuz etkileri açısından belirli diller, kültürler ve deneyimlerin sınırlarını ve kısmiliğini öğrenmek anlamını da taşır (Frierch and Giroux,1989 Akt: Callahan,2001, s.IX). Bu bağlamda medya okuryazarlığ bilinçli, yansıtıcı ve katılımcı bireyler yetiştirilmesini amaçlar (Scheıbe and Rogow,2012, s.257).

Yansıtıcı düşünme, bir şüphe veya sorunla başlar ve bir çözüm ile biter. Yansıtıcı düşünür farklı fikirleri karşılaştırır, sorular sorar, kendini ve olayları sorgular, eleştirel düşünebilir, sorunları çözebilir ve bağımsız olarak karar verebilir (Kuş,190). Bu ifadeden yola çıkılarak medya okuryazarlığı ve yansıtıcı düşünme arasında kolaylıkla ilişki kurulabilir. Çünkü medya okuryazarlığı eğitiminin merkezinde medya metinleri hakkında soru sorma eylemi olan araştırma pedagojisi vardır (Hobbs, 2006, s.27). Yansitıcı öğretmenler de sürekli öğrenmeye ve gelişime bağlılığı teşvik eden bir araştırma yaklaşımını uygularlar (Carey, 2017, s.8). Sembolik metinlere karşı açık bir sorgulama, yansıtıcı ve eleştirel duruşun geliştirilmesi, medya okuryazarlığı şemsiyesinin merkez kutbunu oluşturur (Hobbs,2006, s.27). Tipkı yansitıcı düşünme de olduğu gibi medya okuryazarlığında da önemli olan şey, her şeye şüpheyle bakılması, daha fazla soru sorulması (Gillmor, 2008, s.4), alınan ve oluşturulan mesajlar hakkında aktif sorgulama ve eleştirel bir düşünme olması gerekliliğidir (NAMLE,2007).

Medya okuryazarlığ1 eğitimcileri kişilere ne düşüneceklerini değil nasıl düşüneceklerini öğretirler (Silverblatt, 2018, s.66). Dolayısıyla düşünme şeklimizi düşünmek, düşünmeyi düşünmek, düşünmemizin ne kadar etkili olduğunu, güçlü yanlarının neler olduğunu, bazen yanlış gittiğini ve en önemlisi nasıl geliştirilebileceğini düşünmek ve değerlendirmek önemlidir (Butterworth ve Thwaites, 2013, s.2).

Yansitıcı düşünme, bireyin günlük yaşantıları ile varsayımlarını incelemesini ve farkında olmasını, kendi içinde bulunduğu durumu eleştirel olarak değerlendirmesini içerir (Finlay, 2008, s.1). Günümüzde 
medya bireyin günlük hayatının neredeyse tamamını oluşturmakta doğrudan ya da dolaylı bir şekilde yaşantısının içinde yer almaktadır. Dolayısıyla bireylerin yaşantılarını aktif bir şekilde sorgulaması aslında çevresini saran medyayı sorgulaması, araştırması şeklinde düşünülebilir. Kararlarını bu araştırma, sorgulama ve derinlemesine düşünme neticesinde alan bireyler gelecekteki yaşantılarında aldıkları kararlardan daha az pişmanlık duyacaklardır.

Dewey (1933, s.10), her yansitıcı işlemde yer alan bazı alt süreçler olduğunu ifade etmiştir. Bu süreçlerin; şaşkınlık, tereddüt, şüphe ve önerilen inancı desteklemek ya da geçersiz kılmak için diğer gerçekleri ortaya çıkarmaya yönelik bir araştırma veya soruşturma eylemi olduğunu açıklamıştır. Medya okuryazarlığı da etrafımızda olup bitenlerle ilgili edilgen ve savunmasız olmamayı, sorgulamayı, şüphe duymayı (Thoman, 1999, s.50) araştırma yapmayı ve bunun neticesinde bir karara varmayı gerektirmektedir. İyi bir medya okuryazarı karşılaştığı şeylere şüpheyle bakar, hiçbir zaman medyadan okunan, görülen veya duyulan şeylerin tümüyle güvenilir olduğunu söylemez (Gillmor, 2008, s.4-6).

Medya okuryazarlığı ve yansitıcı düşünme esasında birbirinden bağımsız iki ayrı beceridir. Ancak medya mesajlarına bu iki becerinin gerekliliklerini birleştirerek baktığımızda çok daha sağlıklı bir sonuca varacağımız söylenebilir. Örneğin, medyada karşımıza çıkan bir reklam, öncelikle medya okuryazarlığı ilkeleri esas alınarak oluşturulan beş anahtar soru kapsamında değerlendirilebilir. Bu mesajı kimin oluşturduğunu, mesajın neden gönderildiğini, mesaja dikkat çekmek için hangi yaratıcı tekniklerin kullanıldığını, mesajda gözden kaçırılan değerleri ve bakış açıların bilerek reklam üzerinde düşünülebilir. Bu soruların cevabı bulunduktan sonra medya mesajının sorgulanmasına yansıtıcı düşünmenin gereklilikleri ile yani aktif, kalıcı ve dikkatli bir düşünme ile devam edilebilir. Kişi, geçmişte ve o an geçirdiği yaşantılar hakkında derinlemesine düşünerek yani kendi deneyimlerini de işin işine katarak bu sorgulama ve değerlendirme işine devam edebilir ve bu şekilde gelecekteki yaşantılarını daha kolay kontrol altına alabilir. Kişi geçmişte bir reklamdan etkilenerek aldığı bir ürünü, memnuniyetini ya da şikâyetini, ani kararının getirdiği sonuçları, bir sorgulama neticesinde karar verseydi bu kararın mevcuttan farklı ne gibi sonuçlar doğuracağını 
derinlemesine düşünür. Böylelikle geçmiş yaşantılarından aldığı dersleri gelecekteki kararlarına ya da yaşantılarına yansıtabilir.

Medya belirli kişileri ve olayları yalnızca göstererek diğerlerinden daha önemli olduğuna işaret eder. Dolayısıyla medya bu süreci, ideolojik olarak masum olduğu düşünülen bir "gerçeği" sunarak yürütür. O halde "seçim" medya eğitiminde önemli olan kavramlardan biridir (Masterman, 2005, s.115). Dolayısıyla medya okuryazarlı̆̆ında amaç, bir bakıma kişilerin doğru seçimi yapmasını ve doğru kararlar almasını sağlamaktır. Bunun içinde kişi medya okuryazarlı̆̆ perspektifinden medya mesajlarına bakmakla birlikte geçmiş yaşantılarından öğrendiklerini de kararlarına yansıtarak bu iki becerinin gerektirdiği sorgulamaları birlikte yapabilir.

Medya okuryazarlığının amacl; her yaştan bireyin eleştirel bir düşünür, etkili bir iletişimci ve günümüz dünyasında aktif bir vatandaş olması için ihtiyaç duydukları sorgulama alışkanlıklarını ve ifade becerilerini geliştirmelerine yardımcı olmaktır (Scheibe ve Rogow, 2012, s.60). Yansitıcı düşünmenin amacı ise derinlemesine düşünerek bir sorunu çözmek veya kafa karıştırıcı bir durumu anlamlandırmak, (Lougran, 1996, s.13) herhangi bir inancı veya sözde bilgi biçimini, onu destekleyen gerekçeler ve muhtemel sonuçlar ışığında, aktif, kalıcı ve dikkatli bir şekilde düşünmektir (Dewey, 1933, s. 6). Bu amaçlar bağlamında baktığımızda yansıtıcı düşünebilen bir birey, medyada karşılaştığı bir inanc1, sözde bilgi biçimini ya da sorunu çözmek ve kafasında karışıklığa sebep olan durumu aydınlatmak için dikkatli ve eleştirel bir şekilde düşünür ve aktif bir sorgulama içerisinde bulunur. $\mathrm{Bu}$ düşünme ve sorgulama neticesinde medyadaki bütün yönlendirme ve yönetme faaliyetlerinin farkına varır. Medyadan aldığı mesajları doğru bir şekilde yorumlayıp, gerçeklik ve kurgusallık arasında ayrım yapar. Medyadaki bu yönlendirmelere rağmen yaptığı yansıtıc1 düşünme, aktif sorgulama ve geçmiş yaşantılarından aldığı deneyimler neticesinde kendi kararını bilinçli bir şekilde verir.

Yansıtıcı düşünme, öğrenmeyi ve uygulamayı geliştirici gücüne rağmen, mesleki veya günlük yaşamımızda yeteri kadar yer almamaktadır. Çünkü yansıtma yapmak için aktif olarak zaman ve çaba harcamak gerekir. Günlük hayatta kendiliğinden yapılan tek düşünme bir şeyler ters gittiğinde, başarısızlıktan korkulduğunda ya da büyük bir 
yaşam krizinden sonra olur (Gelter, 2003, s.337). Dolayısıyla öğrencilere, yansıtıcı düşünmeyi yaşamlarında daha sık kullanmaları gerektiğinin bilinci kazandırılmalıdır. Yapılandırıcı yaklaşımda öğretimin temel hedeflerinden biri yansıtmanın gerçekleşmesidir. Bunun için öğretmenin gerek örneklerle gerekse ödevlerle öğrencileri teşvik etmesi gerekir. Öğretimin temel amaçlarından biri öğrencileri problem çözme becerilerini geliştirmeleri yönünde teşvik etmek, örnek durumlarda uyguladığı çözümleri, gerçek hayat deneyimlerine yansıtma becerilerini geliştirmektir (Başol ve Gencel, 2013, s.930). Yansıtıcı düşünme olmadan öğretmenlerin öğretim uygulamaları durgun ve rutin hale gelmektedir (Carey,2017, s.28). Yansitıcı düşünme ile ilgili etkinlikler, medya okuryazarlığını içinde barındıran konularla ve medya okuryazarlığı dersleriyle kolaylıkla ilişkilendirilebilir. Gerek her iki becerinin de sorgulamaya dayalı olması gerekse amaçlarından yola çıkarak yapılan değerlendirmeler böyle bir sonuca varılmasını kolaylaştırmaktadır.

Medya okuryazarlığ eğitiminde, öğretmenin canlı, demokratik, grup odaklı ve eyleme dönük öğretim metotları ile yansıtıcı ve eleştirel düşünmeyi teşvik etmesi önemlidir (Masterman, 2005, s.24). Çünkü bu teşvik öğrencileri düşünmeye zorlayarak kanıta dayalı düşünmelerini ve eyleme geçmelerini sağlar (Sperry ve Baker, 2016, s.183). Ayrıca öğretmenlerin yansitıcı düşünme becerilerine sahip olmaları, bu becerilerden mesleki hayatlarında faydalanabilmeleri ve bu becerileri öğrencilerine de öğreterek, öğrenme süreçlerinde deneyimlerinden sonuçlar çıkarmaları da önemlidir (Ceran, 2016, s.227). Yansitıcı düşünme; öğretmenlerin mesleki açıdan gelişimini ve gelişim sürecini denetlemelerine yardımcı olup, öğrenciler için ilgi çekici bir öğrenme ortamı oluşturmalarına da fırsat vermektedir (Ünver, 2011, s.138).

Yansıtıcı düşünme, öğretmenlerin "geleneksel, alışılmış düşünme ve davranış biçimlerinin altında yatan varsayımları sorgulamalarını ve daha sonra bu eleştirel sorgulamaya dayanarak farklı düşünmeye ve harekete geçmeye hazır olmalarını" gerektirir (Brookfield, 1987, s.1) . Yansıtıcı düşünme için tek başına öğrenme yeterli olmayıp öğrencilerin bilgiyi yaşamlarında uygulaması yani davranışa dönüştürebilmesi gerekmektedir (Kuş, s.190; Ceran,2016, s.930). Bu bağlamda öğrencilerin güvenini, grup diyaloğu yoluyla geliştirebilecek, kendi kararlarını verip, bu kararları analiz edebilecek ve böylece kendi öğrenme ve 
düşünmelerinin sorumluluklarını alabilecek yaklaşımlar geliştirmek önemlidir (Masterman, 2005, s.25). Böylelikle medya okuryazarlığı, sosyal yaşamın inşası üzerinde bir etki yaratmanın yolu haline gelir ve bu etki sayesinde medya okuryazarlığı yansıtıcı bir alışkanlık ya da uygulama haline gelebilir (Şahin, 2002, s.72). Öğretmenin burada önemli bir rolü vardır. Öğretmenin görevi öğrencileri sahip oldukları düşünceler hakkında şüphe duymalarına yardımcı olmak ve sorgulama yeteneklerini geliştirmektir (Masterman, 2005, s.25).

Cheung (2016, s.35-36), yansitıcı öğretimin, öğretmenlerin eğitimsel kararlarında daha aktif rol almalarını sağladığından, medya okuryazarlığ 1 eğitimi gibi bir eğitim yeniliğinin benimsenmesiyle son derece ilgili olduğunu ifade etmiştir. Yansıtıcı öğretimin, öğretmenlerin kendi uygulamalarını analiz etmesini, tartışmasını, değerlendirmesini ve değiştirmesini sağlamayı amaçladığını ve öğretmenleri kendi mesleki gelişimleri için daha fazla desteklediğini belirtmiştir.

Medya okuryazarlığı ve yansıtıcı düşünme arasındaki ilişkinin belirlenmesine dönük literatürde herhangi bir araştırmaya ve kuramsal bir çalışmaya rastlanmamıştır. Bu çalışma ile medya okuryazarlığı ve yansıtıcı düşünme arasındaki ilişkinin açıklanması amaçlanmıştır. Çalışmanın yapılacak kuramsal çalışmalara da temel oluşturması beklenmektedir. Yapılacak çalışmalar ile bu ilişkininin yönü ve büyüklüğü hakkında yargıya varabilir, mevcut ilişkinin nedenleri sorgulanabilir ya da ders başarılarına katkıları ortaya konulabilir.

\section{Sonuç}

Medyada karşılaşılan sözlü ve görsel sembollerden kişisel anlam oluşturma, medya ortamı ile eleştirel olarak başa çıkma yetkinliği olarak ifade edilen medya okuryazarlığı bireylerin bir takım üst düzey düşünme becerilerine sahip olmalarını gerektirmektedir. Medya okuryazarlığ 1 becerisine sahip bireylerin eleştirel düşünme becerisine de sahip olmaları önemli görülmüş ve bu doğrultuda farklı amaçta ve kapsamda çalışmalar yapılmıştır. Ancak farklı düşünme becerileri ile medya okuryazarlığı arasındaki ilişkinin ortaya çıarılmasının da literatüre katkı sağlayacağı düşünülmektedir. Bu bağlamda bu araştırmada medya okuryazarlığı ile yansıtıcı düşünme arasında bir bağ 
kurularak bireylerin, medyanın etkisiyle aldıkları kararlarında yansitıcı düşünmelerinin önemi ortaya konulmaya çalışılmıştır. Yansıtıcı düşünmenin, yeni anlayışlar kazanmak, bireyin gelecekteki yaşantılarını geliştirmek ve tekrar ele almak yönündeki amacı burada önemli bir çıkış noktası olmuştur. Çünkü birey yansıtıcı düşündüğü zaman ani bir hareketle düşüncelerini oluşturmaz, alternatifleri dikkate alarak mevcut durumları gözden geçirir ve bir karar almadan önce bu kararın gelecekteki yaşantısını nasıl etkileyeceğini derinlemesine düşünür. Karşılaştığ medyada karşımıza çıkan her türlü sözlü ve görsel semboller için kullanmamız alacağımız kararların doğru olması noktasında bize yardımcı olacaktır. Geçmiş yaşantılarımızdan aldığımız deneyimlerimizi işin içine katarak düşündügümüzde daha sağlıklı kararlar vereceğimiz muhakkaktır. Çünkü yansıtıcı düşünme, bir sonuca ya da düzeltilmek istenen bir hedefe yöneliktir. Bunun için de kişinin geçmiş yaşantılarından deneyimler çıkararak gelecekteki hayatına yön vermesi amaçlanmaktadır. Yansıtıcı düşünebilen medya okuryazarı bireyler yetiştirmek öncelikle bu niteliklere sahip öğretmenlerin yetiştirilmesi ile mümkün olacaktır. Bu da öğretmenlerin hizmet öncesi aldıkları eğitim ile ilişkilidir. $\mathrm{Bu}$ kapsamda yapılan çalışmalar arttıkça yansıtıcı düşünebilen medya okuryazarı bireylerin yetiştirilmesi yönünde çalışmalar da yapılacaktır. Bu araştırmanın yansıtıcı düşünme ile medya okuryazarlığı arasındaki ilişkinin ortaya konulmasını amaçlayan kuramsal ve deneysel araştırmalara temel oluşturması beklenmektedir. 


\title{
EXTENDED ABSTRACT
}

\section{Media Literacy and Reflective Thinking: A Conceptual Overview}

\author{
Ayşegül Yılmazer- Ünsal Bekdemir \\ Recep Tayyip Erdoğan University- Giresun University
}

Considering the studies on media literacy and thinking skills, it is seen that the studies mostly focus on critical thinking skills. However, critical thinking is only one of the thinking skills, and it is thought that it is also important to reveal the relationship between other thinking skills and media literacy. In this context, the purpose of this study is to reveal the relationship between reflective thinking, which is one of the thinking skills, and media literacy, and to give a general point of view on the subject.

In the research, document analysis technique which is one of the qualitative analysis methods was used. Document review covers the analysis of written materials containing information about the facts and events aimed to be investigated.

When the concepts of media literacy and reflective thinking are examined comprehensively, it is seen that there are many common features between the two concepts or skills. In this study, which tries to reveal the relationship between these two skills, which have common characteristics, the following questions are sought:

- What is media literacy?

- What is reflective thinking?

- What kind of a relationship can be established between media literacy and reflective thinking in a conceptual framework?

Media literacy, which aims to help individuals of all ages develop the questioning habits and expressive skills they need to become a critical thinker, effective communicator, and active citizen in today's world (Schebe and Rogow, 2012, p.60) includes "reading" and "writing" the media. While it enables young people to make knowledge-based judgments and comments as media consumers, it also enables them to become a media producer on their own (Meigs, 2006, p.20). 
Today, it is more important to process and examine information than knowing it. For this reason, the education system aims to provide students with thinking skills (Bacanl, 2012, p.30). It can be said that media literacy is based on the view that individuals should be more conscious of media consumption and have some thinking skills (Kurt and Kürüm, 2010, p.21). Many people studying media literacy consider media literacy primarily as a skill and use the concept of critical thinking to refer to this skill (Potter, 2016, p.59). However, critical thinking is only one of the thinking skills, and it is considered that it is important for different thinking skills to refer to media literacy. It is considered important that different thinking skills also refer to media literacy. One of these thinking skills is reflective thinking. Reflective thinking is a more comprehensive way of thinking that includes critical thinking, and critical thinking can be considered the product of reflective thinking. (Altın and Saracaloğlu, 2018, s.6). Reflective thinking means thinking deeply, seriously, and in a way of being concentrated about something beyond giving immediate responses to stimuli. When reflection is made, thoughts are not only created with a sudden movement, also alternatives are taken into consideration, conclusions are drawn, existing evidence is discussed, and hypotheses are tested (Butterworth and Thwaites, 2013, p.2).

Reflective thinking begins with a doubt or problem and ends with a solution. Reflective thinkers compare different ideas, ask questions, question themselves and events, can think critically, solve problems, and make decisions independently (Kuş, p.190). Based on this statement, a relationship can easily be established between media literacy and reflective thinking. It is because research pedagogy, which is the act of asking questions about media texts, is at the center of media literacy education (Hobbs, 2006, p.27). Reflective teachers apply a research approach that encourages continuous learning and development (Carey, 2017, p.8). An open questioning against symbolic texts and the development of a reflective and critical style constitute the center of the umbrella of media literacy (Hobbs, 2006, p.27). Just as in reflective thinking, it is also important in media literacy to suspect everything, ask more questions (Gillmor, 2008, p.4), actively question and critically think about the messages received and generated (NAMLE, 2007). 
The media points out that certain people and events are more important than others only by showing them. Therefore, the media manages this process by presenting a "truth" that is thought to be ideologically innocent. Therefore, "choice" is one of the important concepts in media education (Masterman, 2005, p.115). Therefore, the purpose of media literacy is to ensure that people make the right choice and make the right decisions. In this context, in addition to approaching the media messages from a perspective on media literacy, one can reflect what they have learnt from their previous experiences in their decisions and make inquiries that these two skills require together.

Reflective thinking includes examining and being aware of the individual's daily life and assumptions, and critically evaluating his / her own situation (Finlay, 2008, p.1). Today, the media constitutes almost all of the daily life of the individual, and is included, directly or indirectly, in his / her life. Therefore, individuals' active questioning of their lives can actually be considered as questioning and researching the media that surrounds them. Individuals who make their decisions as a result of this research, questioning, and reflection will regret less about the decisions they will make in their future lives.

The purpose of media literacy is to help individuals of all ages develop the questioning habits and expressive skills they need to become a critical thinker, effective communicator, and active citizen in today's world (Scherbe and Rogow, 2012, p.60). The purpose of reflective thinking is to solve a problem or make sense of a confusing situation by thinking deeply (Lougran, 1996, p.13), and to think any belief or pseudoinformation actively, permanently and carefully in the light of the reasons and possible consequences that support it (Lougran, 1996, p.13) ( Dewey, 1933, p.6). In the context of these purposes, individuals, who can think reflectively, think carefully and critically in order to solve a belief, pseudo information, or a problem they encounter in the media and to illuminate the situation that causes confusion, and actively question them. As a result of this thinking and questioning, they become aware of all the directing and managing activities in the media. They correctly interpret the messages they receive from the media and distinguish between reality and fiction. Despite these inducements in the media, 
they can make their own decisions consciously as a result of reflective thinking, active questioning, and their previous experiences.

Media literacy and reflective thinking are essentially two separate skills that are independent of each other. However, when we approach the media messages by combining the requirements of these two skills, it can be said that we will reach a much healthier conclusion. For example, an advertisement that we encounter in the media can be evaluated within the scope of five key questions that are based on the principles of media literacy. After finding the answers to these questions, the questioning of the media message can be continued with the requirements of reflective thinking, namely active, permanent and careful thinking. By thinking deeply about the past and present experiences and considering their own experiences, individuals can continue the questioning and evaluation, thus taking control of their future lives more easily.

\section{Kaynakça/References}

Altın, M. ve Saracaloğlu, A. S. (2018). Yaratıcl, eleştirel ve yansıtıcı düşünme: Benzerlikler-farkl1liklar. International Journal of Contemporary Educational Studies, 4(1), 1-9.

Altun, A. (2010). Medya okuryazarlğ̆ını sosyal bilgiler programlarıla ilişkilendirilmesi ve öğretimi. Yayımlanmamış doktora tezi. Gazi Üniversitesi, Eğitim Bilimleri Enstitüsü, Ankara.

Altıntaş, S. (2019). Sosyal bilgiler öğretmen adaylarının eleştirel düşünme eğilimleri ile medya okuryazarlik düzeyleri arasındaki ilişki. Yayımlanmamış yüksek lisans tezi. Bursa Uludağ Üniversitesi, Eğitim Bilimleri Enstitüsü, Bursa.

Ankaralıgil, S. Y. (2009). İlköğretim 6. ve 7. sinıf öğrencilerinde medya okuryazarlı̆̆ ve eleştirel düşünme üzerine bir araştırma. Yayımlanmamış yüksek lisans tezi. İstanbul Üniversitesi, Sosyal Bilimler Enstitüsü, İstanbul.

Aufderheide, P. ve Firestone, C. (1992). Media literacy a report of the national leadership conference on media literacy. Maryland: The Aspen Institute.

Aybek, B. (2016). The relationship between prospective teachers media and television literacy and their critical thinking dispositions. Eurasian Journal of Educational Research, 63, 261-278.

Aybek, B. ve Demir, R. (2013). Lise öğrencilerinin medya ve televizyon okuryazarlık düzeyleri ile eleştirel düşünme eğilimlerinin 
incelenmesi. Çukurova Üniversitesi Sosyal Bilimler Enstitüsü Dergisi, 22(2), 287-304.

Bacanlı, H. (2012). Dört katlı düşünme modeli. Bilim ve Aklın Aydınlı̆ında Eğitim, 146, 29-36.

Bakan, U. (2010). Illköğretim medya okuryazarlığı dersinin öğrencilerin eleştirel düşünme becerilerine etkisi. Yayımlanmamış yüksek lisans tezi. Atatürk Üniversitesi, Sosyal Bilimler Enstitüsü, Erzurum.

Bergsma, L. J. (2002). Media literacy and prevention: going beyond "just say no." Thinking critically about media: Schools and families in partnership içinde. (s.13-18) Alexandria: Cable in the Classroom.

Bilici, İ. E. (2017). Medya okuryazarlığı ve eğitimi. Ankara: Nobel.

Boud, D., Keogh, R. ve Walker, D. (2005). Reflection: Turning experience into learning. London: RoutledgeFalmer.

Brookfield, S. (1987). Developing critical thinkers: challenging adults to explore alternatives ways of thinking and acting. Francisco: CA: Jossey- Bass.

Butterworth, J. ve Thwaites, G. (2013). Thinking skills critical thinking and problem solving. Cambridge: Cambridge University Press.

Carey, S. F. (2017). The meaning of reflective teaching to national board certified teachers. Texas: Proquest.

Carlsson, U. (2019). Understanding media and information literacy (mil) in the digital of democracy. Göteborg: Department of Journalism, Media and Communication (JMG).

Celot, P. (2010). Study on assessment criteria for media literacy levels. Brussels: EAVI.

Ceran, E. (2017). Deneyimlerimizden öğrenmek: yansitıcı düşünme. N. Kuyumcu (Ed.) Kuram iyide sinıfta ne yapmalı? Öğretmenin El Kitabı içinde (s.226-253). İstanbul: E Yayınları.

Cheung, C.-K. (2016). Media literacy education in chine. Springer.

Çarkıt, C. (2019). 2018 ortaokul medya okuryazarlı̆̆1 dersi öğretim programının eleştirel düşünme bağlamında değerlendirilmesi. Sosyal Bilimler Dergisi, 6(38), 202-213.

Çelik, Ö., Çokçalışkan, H. ve Yorulmaz, A. (2018). Investigation of the effect of pre-service classroom teachers' critical thinking disposition on their media literacy. International Journal of Evaluation and Research in Education, 7(3), 194-202. 
Dalgıç, G. (2011). Okul yöneticilerinin yansıtıcı düşünme beceri ve uygulamalarının incelenmesi: Istanbul ve Kopenhag örneği. Yayımlanmamış doktora tezi. Marmara Üniversitesi, Eğitim Bilimleri Enstitüsü, İstanbul.

Dewey, J. (1933). How we think a restatement of the relation of reflective thinking to the educative process. Lexington: Columbia University.

Erişti, B. ve Erdem, C. (2018). Öğretmen adaylarının medya okuryazarlığı beceri düzeyleri ile eleştirel düşünme eğilimleri arasındaki ilişki. Elektronik Sosyal Bilimler Dergisi, 17(67), 1234-1251.

Ersözlü, Z. N. (2008). Yansıtıcı düşünmeyi geliştirici etkinliklerin ilköğretim 5. sınıf öğrencilerinin sosyal bilgiler dersindeki akademik başarılarına ve tutumlarına etkisi. Yayımlanmamış doktora tezi. Fırat Üniversitesi Sosyal Bilimler Enstitüsü, Elazı̆̆.

Feuerstein, M. (2002). Media literacy in support of critikal thinking. Ann Arbor: The Universy of Liverpool.

Finlay, L. (2008). Reflecting on 'reflective practice'. Practice- based Professional Learning Paper 52, 1-28.

Gelter, H. (2003). Why is reflective thinking uncommon. Reflective Practice, 4(3), 337-344.

Gillmor, B. D. (2008). Principles for a new media literacy. Berkman Center for Internet and Society, Harvard University.

Gough, D. (1991). Thinking about thinking. National Association Of Elementary School Principals, 2(2), 1-4.

Güneş, F. (2012). Öğrencilerin düşünme becerilerini geliştirme. TÜBAR, 127-146.

Güney, K. (2008). Mikro-yansıtıcı öğretim yönteminin öğretmen adaylarının sunu performansı ve yansıtıcı düşünmesine etkisi. Yayımlanmamış doktora tezi. Frrat Üniversitesi, Sosyal Bilimler Enstitüsü, Elazı̆̆.

Hardiyanti, R. A. (2018). Developing media literacy ability in social studies learning. The 3rd International Seminar on Social Studies and History Education (s.499-508). Universitas Pendidikan Indonesia Nana Supriatna.

Hobbs, R. (2010). Digital and media literacy: A plan of action. Washington: The Aspen Institute.

Judge, B., Jones, P. ve McCreery, E. (2009). Critical thinking skills for education studuents. Learning Matters.

Karaboğa, M. T. (2017). Eleştirel bakış açısıyla medya okuryazarlı̆̆ı. 2. Mediterranean International Congress on Social Sciences (MECAS II). Ohrid: International Vision University. 
Karaman, M. (2016). Öğretmen adaylarının medya okuryazarlık düzeyleri ve eleştirel düşünme eğilimleri üzerine bir araştırma. Gümüşhane Üniversitesi İletişim Fakültesi Elektronik Dergisi, 4, 326-349.

Kıral,B. (2020). Nitel bir veri analizi yöntemi olarak doküman analizi. Sosyal Bilimler Enstitüsü Dergisi, 15, 170-189.

Kurt, A. A. ve Kürüm, D. (2010). Medya okuryazarlığ 1 ve eleştirel düşünme arasındaki ilişki: Kavramsal bir bakış. Mehmet Akif Ersoy Üniversitesi Sosyal Bilimler Enstitüsü Dergisi, 2, 20-34.

Larrive, B. (2000). Transforming teaching practice: Becoming the critically reflctive teacher. Reflective Practice, 1(3), 293-307.

Lewis, J. ve Jhally, S. (1998). The struggle over media literacy. Journal of Communication, 40, 109-120.

Longman. (2020). Dictionary of contemporary english. Pearson Longman.

Loughran, J. J. (1996). Developing reflective practice: Learning about teaching and learning through modelling. London: Washington D.C.

Masterman, L. (2005). Teaching the media. Routledge.

Meigs, D. F. (2006). Media education a kit for teachers, students, parents and professionals. Paris: Unesco.

Nalçatı, A. Meral, E. ve Şahin, İ. F. (2016). Sosyal bilgiler öğretmen adaylarının eleştirel düşünme ile medya okuryazarlıkları arasındaki ilişki. Doğu Coğrafya Dergisi, 36, 1-12.

NAMLE. (2007). 03. 08. 2020 tarihinde https://namle.net/publications/medialiteracy-definitions/ adresinden alındı.

Özden, Y. (1999). Öğrenme ve öğretme. Ankara: Pegem Yayıncllı.

Potter, W. J. (2016). Media literacy. London: Sage.

Quin, R. ve McMahon, B. (2001). Media literacy in the information age: Current perspectives. R. Kubey (Ed), Living with the tiger: Media curriculum issues for the future (s.307-321). New Brunswick: Transaction.

Rodgers, C. (2002). Defining reflection: Another look at john dewey and reflective thinking. Teachers College Record, 104(4), 842-866.

Scheibe, C. ve Rogow, F. (2012). The teacher's guide to media literacy critical thinking in a multimedia world. Corwin.

Silverblatt, A. (2018). Media literacy and critical thinking. International Journal of Media and Information Literacy, 3(2), 66-71.

Sperry, C. ve Baker, F. W. (2016). Media literacy. Social Education National Council for the Social Studies, 80(3), 183-185. 
Şahin, A. (2002). Understanding media literacy: An in-depth analysis of media educators understanding and teaching of media literacy . New Mexico: New Mexico State University.

Thayer, C. M. (2006). The impact of a media literacy program on critical thinking and writing in a high school to production classroom. Dissertation. California: Touro University International College Of Education Cypress.

Thoman, E. (1999). Skills and strategies for media education. Educational Leadership, 56(5), 50-54.

Thoman, E. (2003). Media literacy: A guided tour of the best resources for teaching. The Clearing House, 76(6), 278-283.

Thoman, E. ve Jolls, T. (2005). Literacy for the 21. century an overview $\mathcal{E}$ orientation guide to media literacy education. Center for Media Literacy.

Tican, C. (2013). Yansıtıcı düşünmeye dayalı öğretim etkinliklerinin öğretmen adaylarının yansıtıcı düşünme becerilerine, eleştirel düşünme becerilerine, demokratik tutumlarına ve akademik başarılarına etkisi. Yayımlanmamış doktora tezi. Gazi Üniversitesi Eğitim Bilimleri Enstitüsü, Ankara.

Tok, Ş. (2008). Yansıtıcı düşünmeyi geliştirici etkinliklerin öğretmen adaylarının öğretmenlik mesleğine yönelik tutumlarına, performanslarına ve yansıtmalarına etkisi. Eğitim ve Bilim, 33(149), 104-117.

Tyner, K. (1991). The media education elephant. 12.09.2020 tarihinde https://www.medialit.org/reading-room/media-education-elephant adresinden alınd.

Ulu, H. ve Baş, Ö. (2020). Öğretmen adaylarının sosyal ağ sitelerini kullanım amaçları, eleştirel düşünme eğilimleri ve medya okuryazarlıkları arasındaki ilişkiler. Hacettepe Üniversitesi Ĕ̆itim Fakültesi Dergisi, 35(3), 556-574.

Ünver, G. (2011). Yansıtıcı düşünme. Ö. Demirel (Ed), Eğitimde yeni yönelimler içinde. (s.137-148). Ankara: Pegem Akademi.

Warlick, D. F. (2004). Redefining literacy for the 21st century. Library of Congress Cataloging-in-Publication Data.

Yıldırım, A., ve Şimşek, H. (2018). Sosyal bilimlerde nitel araştırma yöntemleri (11. Bask1). Ankara: Seçkin.

Yüzgeç, A. Y. (2020). The relationship between critical thinking dispositions of prospective english language teachers and their levels of new media literacy. 
Yayımlanmamış yüksek lisans tezi. Başkent Üniversitesi, Eğitim Bilimleri Enstitüsü, Ankara.

\section{Kaynakça Bilgisi / Citation Information}

Yılmazer, A. ve Bekdemir, Ü. (2021). Medya okuryazarlığ1 ve yansıtıc1 düşünme: Kavramsal bir bakış. OPUS- Uluslararası Toplum Araştırmaları Dergisi, 18(43), 6839-6867. DOI: 10.26466/opus.938232. 